\title{
Case Analysis on Risk Management Process in Public Safety of Grassroots Organization Based on ISO 31000
}

\author{
Wei Zhu, Yafei Wang, Yingnan Ma, Hui Lyu \\ Beijing Research Center of Urban System Engineering, Beijing 100035, China
}

\section{基于 IS031000 的基层组织公共安全风险管理过 程实例分析}

\author{
朱伟, 王亚飞, 马英楠, 吕慧 \\ 北京城市系统工程研究中心, 北京 100035 , 中国
}

\begin{abstract}
In view of the lack of specific implementation details of the ISO31000 risk management process, the present paper carries out a case study of the ISO31000 standard in the implementation of the public security risk management process. The paper expounds the every stage of the risk management process and the input and output parameters, and the application of generics risk management in grassroots organizations has been clearly presented. The wide application of ISO31000 can be helpful for clearing the risk management of basic level organizations, improving the efficiency of risk management and controlling the risk effectively.
\end{abstract}

Keywords: ISO31000; Risk management; Public safety; Risk assessment; Grass-root organization.

\section{摘要 \\ 针对 ISO31000 风险管理过程缺少具体实施细 节的情况, 本文对 ISO31000 标准的具体实施 在基层组织的公共安全风险管理过程进行了 实例研究, 详细阐述了风险管理过程的各个 阶段的工作内容和输入、输出参数, 清晰的 呈现了全面风险管理在基层组织中的运用。 ISO31000 的广泛应用能够帮助理清基层组织 风险管理的思路、提高风险管理效率、有效 控制风险。}

关键词：ISO31000; 风险管理; 公共安 全; 风险评估; 基层组织

\section{1. 引言}

国际标准化组织 (ISO) 于 2009 年发布 了适用于各种组织的风险管理国际标准 ISO31000:2009 《风险管理: 原则与指南》 ${ }^{[1]}$ ( 以下简称 ISO31000), 是一个全面风险管 理标准。ISO31000 明确了各种组织在风险管 理中的一些基本定义、一般性原则、过程和 框架。其首要原则是, 提升正面风险和降低 负面风险, 为组织创造价值。之所以有“正 面风险”和“负面风险”只说, 是因为在 ISO31000 中对“ 风险”有全新的定义, 即 “不确定性对目标的影响”, “影响”具有两 个不同的方面：正面的影响——促进目标的 实现; 负面的影响——阻碍目标的实现。这 表明“风险”被赋予了两重性。其过程列出 了组织在进行风险管理中的各项步骤, 框架 规定了风险管理中的组织机构、或部门设 置。

基层组织公共安全风险管理过程是指通 过风险评估技术来识别风险（这里主要指负 面风险)、分析风险、评价风险, 并采取有效 的手段来应对风险, 以达到相对安全状态的 过程。ISO31000 的全面风险管理是一种站在 整个组织角度所进行的整体化风险管理方 式, 因为一个组织的风险来自多方面, 最终 对组织产生影响的不仅仅是某一种风险, 而 是所有风险综合作用的结果, 所以从组织整 体的角度出发, 才能有效地进行风险管理。

ISO31000 描述了风险管理过程的一般性 步骤, 但具体细节没有说明。关于基层组织 的风险评估, 已经有学者提出了实用性的方 法 $^{[2,3]}$, 本文通过实例分析的方式介绍了 ISO31000 在基层组织公共安全领域进行风险 管理的过程, 详细阐述了某风景区在风险管 
Risk Analysis and Crisis Response in Big Data Era (RAC-16)

理过程关环节的具体内容和产出, 对于组织 的利用 ISO31000 实施风险管理有借鉴意义。

\section{2. 风险管理过程}

2.1 建立环境

通过建立环境, 组织清楚地表达其目 标, 确定内、外部参数(图 1)。

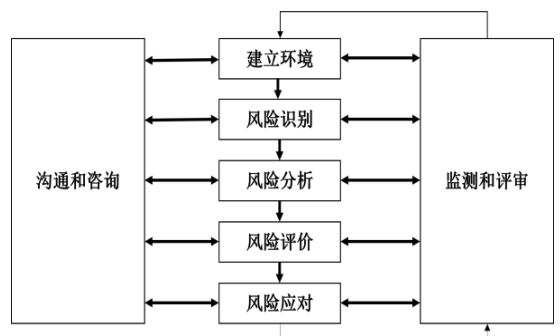

图 1. 风险管理过程

\subsection{1 风景区基本情况}

风景区的突出特点有 “六多”，即：一、 二类大街多, 中央首长驻地多, 部队机关 多, 中央单位多, 文物古迹、旅游景点多, 老旧城区平房院落多。

(1) 居住区、保护区和旅游区 “三区合一”

（2）旅游资源丰富，吸引大量游客

（3）中心地块、承载容量有限、用地资源有 限

（4）公交发达、地铁方便、停车设施缺乏、 交通设施多样化

\section{1.2 存在的安全问题}

（1）客流密度极大

(2) 风险影响因素多

（3）客流管理缺乏科学技术和指导

（4）社会影响重大

\section{2 风险识别}

风险识别的目的是确定风险源、风险事 件、产生原因及潜在后果。形成一个基于风 险事件的全面封面清单。

2.2.1 风险识别办法

（1）现场调研。开展全面调研，对现场 人物环管多个环节的实地情况展开调研, 获 得来自现场的第一手资料。

（2）专家论证。多方征询公共安全领域 专家意见，听取管理部门相关管理人员的意 见和建议。

（3）理论分析。从人物环管四个方面, 运用安全系统工程学的基本原理和方法, 对 地区面临的现实风险逐项排查。

\subsection{2 风险识别登记}

通过风险识别确定风景区的风险类型, 见表 1 。

\section{3 风险分析}

风险要建立对风险的理解, 为风险评 价、是否需要进行风险应对提供基础数据。 考虑风险发生的原因、风险源。后果通过风 险分析, 根据各类风险的可能性和产生后 果, 确定各类风险的风险等级 (表 2)。

\section{4 风险评价}

目的是协助决策, 基于风险分析的结 果, 根据需要对应对的优先顺序进行决策。

经风险分析, 认为地区存在如下风险类 型：水体污染、食品卫生、食物中毒、拥 堵、交通伤害、治安、火灾、踩踏事件、溺 水、极端天气等。现将各风险按照发生的相 对严重性和可能性进行排序, 如图 2 所示。

\section{5 风险应对}

包括选择一个或多个改变风险的方式, 并实施这些方式。风险应对是个循环过程 1) 实施应对措施;

(2) 判断剩余风险的等级是否可容忍;

（3）如果不可容忍，提出新的应对措施;

(4) 评估应对的有效性。

根据风险评估的结果，某景区的火灾、 踩踏风险是不可容忍的, 需要采取应对措 施。应对措施如下:

(1) 什刹海地区大客流安全管理提升工程 ----完善客流监测设备, 建立大客流监测预 警系统

---完善一些重要部位的监测统计。例如: 重要客流风险点, 但是缺乏对其区域的客流 监测统计;

----部分客流监测点经常需要维修, 导致数 据缺失和不完整。

(2) 对客流信息数据的进一步智能分析, 能 实现客流容量、密度、速度等方面的预警功 能, 实现区域大规模的客流引导路线规划和 紧急状态下的应急疏散路线规划, 也未能实 现客流信息化、快速管理。

增设一些重点部位的客流监测设备, 实现重 要区域的全覆盖, 尤其是夜间的客流统计技 术设备; 加强对客流智能分析系统建设, 完 善客流预警分析模块、客流引导模块、客流 紧急疏导模块、数字化预案等模块功能的开 发。

（3）实施交通管理措施，提升游客交通安全 环境;

（4）客流通行隐患整改, 提高游客游览安全 环境; 
Risk Analysis and Crisis Response in Big Data Era (RAC-16)

表 1：风景区风险识别表

\begin{tabular}{|c|c|c|c|}
\hline $\begin{array}{l}\text { 风险 } \\
\text { 因素 } \\
\end{array}$ & 风险源 & 风险事件及原因 & $\begin{array}{l}\text { 可能造成 } \\
\text { 的突发事件 }\end{array}$ \\
\hline \multirow{5}{*}{ 人 } & 游客客流量大 & \multirow{3}{*}{$\begin{array}{l}\text { 违章停车、拥堵 } \\
\text { 对环境不熟悉、盲目从众 } \\
\text { 占道经营、违法经营、影响客流 } \\
\text { 秩序和通行效率 }\end{array}$} & 拥堵/踩踏 \\
\hline & 外地游客 & & 拥堵 \\
\hline & 流动商贩 & & 治安事件、造成拥堵 \\
\hline & 酒吧游客 & 酗酒 & $\begin{array}{l}\text { 治安事件、重大刑事案 } \\
\text { 件 }\end{array}$ \\
\hline & 游客不安全行为 & $\begin{array}{l}\text { 违规游泳、违规垂钓、船上危险 } \\
\text { 动作 }\end{array}$ & 溺水 \\
\hline \multirow{3}{*}{ 物 } & 电气隐患 & $\begin{array}{l}\text { 电气老化、私接乱搭、超负荷使 } \\
\text { 用、消防设施不全 }\end{array}$ & 火灾 \\
\hline & $\begin{array}{l}\text { 易燃物隐患 } \\
\text { 酒吧 } \\
\text { 储气罐 }\end{array}$ & $\begin{array}{l}\text { 液化气储运以及使用环节隐患 } \\
\text { 占道经营 }\end{array}$ & $\begin{array}{l}\text { 火灾 } \\
\text { 拥堵 } \\
\text { 火灾 }\end{array}$ \\
\hline & 障碍物占道 & 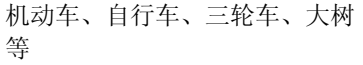 & 摔伤、拥挤踩踏 \\
\hline \multirow{4}{*}{ 环境 } & $\begin{array}{l}\text { 水域面积大 } \\
\text { 游船众多, 航线存在潜在风险 } \\
\text { 路网复杂 } \\
\text { 道路有效宽度小 }\end{array}$ & $\begin{array}{l}\text { 溺水风险加大 } \\
\text { 水上交通拥堵、溺水风险加大 } \\
\text { 客流疏导难度大 } \\
\text { 客流疏导时间慢 }\end{array}$ & $\begin{array}{l}\text { 溺水 } \\
\text { 溺水 } \\
\text { 踩踏事故 } \\
\text { 踩踏事故 }\end{array}$ \\
\hline & 道路关键节点空间有限 & $\begin{array}{l}\text { 银锭桥、前海西街、后海南沿等 } \\
\text { 处谷易拥堵 }\end{array}$ & $\begin{array}{l}\text { 踩踏事故、车辆伤害、 } \\
\text { 溺水 }\end{array}$ \\
\hline & $\begin{array}{l}\text { 沿湖护栏低 } \\
\text { 极端恶劣天气 }\end{array}$ & $\begin{array}{l}\text { 低于人的自重高度 } \\
\text { 暴雨、冰雹、大雪、大风 }\end{array}$ & $\begin{array}{l}\text { 自杀、溺水 } \\
\text { 拥挤踩踏 }\end{array}$ \\
\hline & 应急疏散空间缺乏 & 突发事件下人员疏散难 & $\begin{array}{l}\text { 大客流疏散导致的次生 } \\
\text { 衍生事件 }\end{array}$ \\
\hline \multirow{3}{*}{ 管理 } & 风险排查制度 & $\begin{array}{l}\text { 对占道经营、无证经营、涉水安 } \\
\text { 全、火灾风险、交通安全、客流 } \\
\text { 聚集安全等未形成制度性排查 }\end{array}$ & $\begin{array}{l}\text { 重大刑事案件、重大安 } \\
\text { 全生产事故 }\end{array}$ \\
\hline & 大客流管理方案不足 & $\begin{array}{l}\text { 未对客流风险实施分类分级的管 } \\
\text { 理方案 }\end{array}$ & $\begin{array}{l}\text { 踩踏事故、极端天气次 } \\
\text { 生事故 }\end{array}$ \\
\hline & 安保方案有待完善 & $\begin{array}{l}\text { 安保资源缺乏维护、安保技术力 } \\
\text { 量相对滞后 }\end{array}$ & $\begin{array}{l}\text { 重大刑事案件、重大安 } \\
\text { 全生产事故 }\end{array}$ \\
\hline
\end{tabular}

表 2: 风景区各类风险等级

\begin{tabular}{|c|c|c|c|c|c|}
\hline $\begin{array}{l}\text { 突发事件 } \\
\text { 类型 }\end{array}$ & 主要风险 & 影响对象 & 可能性 & 后果 & $\begin{array}{c}\text { 风险等 } \\
\text { 级 }\end{array}$ \\
\hline \multirow{3}{*}{ 自然灾害 } & 暴雨、冰雹 & 生命、财产受损 & 3 & 2 & 6 \\
\hline & 大风、骤然降温 & 财产受损 & 3 & 1 & 3 \\
\hline & 大雪 & 财产受损 & 2 & 2 & 4 \\
\hline \multirow{7}{*}{ 事故灾难 } & 火灾 & 生命、财产受损 & 3 & 3 & 9 \\
\hline & 车辆伤害 & 生命、健康受损 & 4 & 2 & 8 \\
\hline & 客流拥堵 & 社会影响、公共秩序 & 4 & 2 & 8 \\
\hline & 踩踏事件 & 生命安全、国际影响 & 2 & 4 & 8 \\
\hline & 水体污染 & 影响生态环境 & 1 & 3 & 3 \\
\hline & 游船安全 & 生命安全 & 2 & 2 & 4 \\
\hline & 溺水 & 生命安全 & 3 & 1 & 3 \\
\hline \multirow{2}{*}{ 公共卫生 } & 食品卫生 & 游客健康 & 3 & 2 & 6 \\
\hline & 传染病 & 游客健康 & 2 & 2 & 4 \\
\hline \multirow{3}{*}{ 社会安全 } & 治安事件 & 国际、社会影响 & 3 & 2 & 6 \\
\hline & 酗酒闹事 & 公共秩序 & 3 & 1 & 3 \\
\hline & 涉外案件 & 国际影响 & 2 & 2 & 4 \\
\hline
\end{tabular}




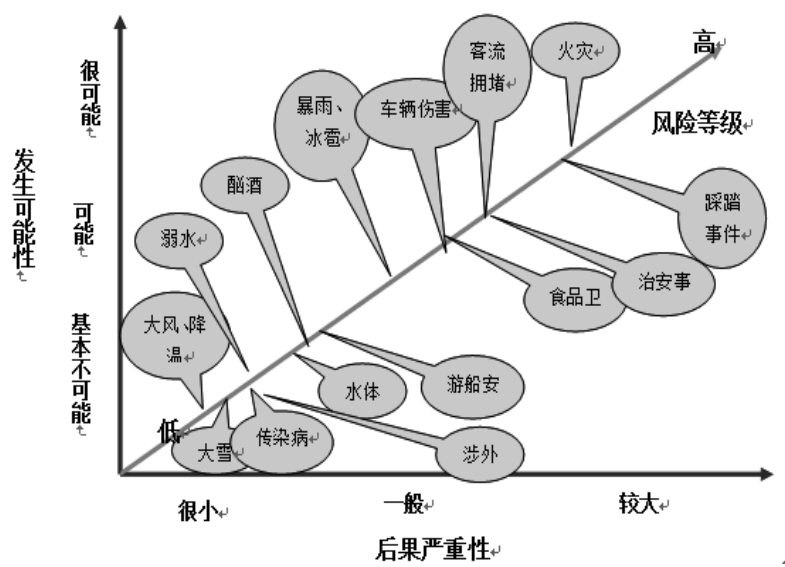

图 2. 风险排序

（5）加强火灾防范, 建立畅通的生命线救灾 网络;

(6) 制定紧急疏散规划, 完善应急导向标识 系统。

\section{6 检测评审}

监测和评审的目的是确保设计和运营两 个方面的控制措施是有效的; 为改进风险评 估获取进一步信息; 在事件、变化、趋势、 成功和失败中进行分析并获取教训; 察觉外 部内部环境变化, 包括风险准则的变化和风 险本身的变化, 有可能影响到风险应对方式 和优先顺序; 识别新的风险。 为:

某风景区在监测和评审环节的工作方式

（1）各职能部门和属地单位结合各自职 能和辖区实际, 认真研究制定本部门、本单 位的工作分方案; 加强相互间的协调配合和 联系沟通, 形成强大的工作合力。

(2) 建立联动会商机制。牵头单位和各 成员单位在每个小长假之前举行会商研讨, 加强沟通联络, 相互通报信息, 建立突发事 件处置联动机制。

（3）加强监督, 落实责任。汼头单位按 照区总体方案要求分别制定分指挥部防控方 案, 报区应急办备案。工作方案应包括指挥 部办公地点、联系人、联系方式、节日期间 领导排班表、工作流程表等。对发现的各类 问题使用照、录像设备进行收集整理并形成 专门材料上报区领导并通报相关部门和属地 责任单位, 确保及时整改, 备存。

（4）加强信息报送。各单位加强值守,
按照统一部署, 加强地区各类情况信息的收 集汇总, 加强与其它职能部门的情况信息的 沟通交流, 对在工作中发现的新情况、新问 题, 要及时上报。

(5) 确保指挥通信安全畅通。城市管理 指挥平台、视频监控系统、电视电话会议系 统、数字 800 兆通信平台、通信应急指挥车 等技术平台全面启用。

\section{3. 结论}

ISO31000 风险管理标准已经发布, 并且 我国也已经等同采用。ISO31000 的全面风险 管理为组织的整体风险管理工作提供有效的 指导。本文将 ISO31000 风险管理过程尝试应 用与基层组织的风险管理, 依据流程化的实 施步骤, 对某风景区的风险识别、风险分 析、风险评估和风险应对做了具体阐述。利 用 ISO31000 能够帮助基层组织的风险管理工 作建立清晰的思路, 从风险源的识别、风险 等级的划分到风险应对优先排序, 做到了对 风险的全面监测和控制。

\section{参考文献}

[1] ISO. ISO 31000:2009, Risk management Principles and guidelines, 2009.

[2] J. Takeshita, H. Mohri. A cooperative game theoretical approach to risk analysis, using network structure, Journal of Risk Analysis and Crisis Response, 2014, 4(1): 43-48.

[3] J. Ma, S.B. Liu, W. Wang, P. Lin, S. Lo. A GIS-based Micro-simulation queue model for vehicle evacuation, Journal of Risk Analysis and Crisis Response, 2(3): 178-187. 